\title{
Vários "Prólogos" para um Journal de Bitita/ Diário de Bitita ou Por que editar Carolina?
}

\author{
Raffaella Andréa Fernandez
}

Como sabemos, as edições brasileiras de Journal de Bitita (1982) são uma cópia do texto estabelecido e traduzido pela jornalista brasileira Clélia Pisa que, em 1972, recebeu das mãos de Carolina Maria de Jesus dois cadernos manuscritos, um com diversos poemas intitulado "Um Brasil" e outro contendo diversas narrativas autobiográficas nomeado "Um Brasil para brasileiros". Esse título, segundo Carolina de Jesus, decorre da frase de Rui Barbosa, repetida por seu avô, o Sócrates africano - que iluminava as parcas mentes daquele pequeno vilarejo em que viviam na cidade de Sacramento- MG, e que cedeu título a uma dessas narrativas.

A edição francesa é uma tradução de Réginet Valbert a partir de tais texto; porém, apresenta acréscimos e correções sugeridas pela editora francesa Métailié, e pela releitura e estabelecimento da jornalista Clélia Pisa. As notas que suportam os textos mudam radicalmente de uma versão para outra, o que denota um direcionamento do texto para cada público selecionado. No caso do francês, principalmente, essas notas enfatizam a História do Brasil para o leitor europeu pouco afeito à realidade dos brasileiros, sobretudo a dos negros descendentes de ex-escravos que ainda viviam o processo desumanizador de segmentação social resultante do preconceito racial.

$\mathrm{Na}$ versão datiloscrita das editoras francesas, os acréscimos que visam o esclarecimento, apresentam diversas oscilações, sinalizando um texto produzido por várias mãos. Esta é uma evidência confirmada pela editora Métaillié em entrevista realizada em novembro de 2013. Nessa ocasião, ela afirmou que a tradutora estava presa ao português e traduzia literalmente o que seria ininteligível para o leitor francês.

As interferências da jornalista brasileira são anotadas como forma de sinalização de veracidade da capacidade de escrita da autora, como podemos ver no final da 
primeira página transcrita quando Carolina de Jesus utilizou um termo em francês na frase: "Eu começava minha avan premièr no mundo"; temos aí a nota (1) da tradutora "em francês no texto". Além disso, Pisa procurou manter no texto datiloscrito alguns desvios gramaticais de Carolina de Jesus, tais como a disposição dos parágrafos, a acentuação, a pontuação, a ortografia, e a grafia do termo francês que ela buscou reproduzir a partir do som de avant-première. Como já foi dito por diversos estudiosos, são muitas as "mesclas de hipoconcordância e hipercorreção" como característica derivada da carência de educação formal somada às referências das literaturas beletristas, brasileira e portuguesa, lidas pela autora. Acrescento a isso que Carolina de Jesus quase sempre escrevia reproduzindo o som das palavras. Enriquecendo seus escritos através dos mecanismos da oralidade e do registro literal da voz repleta de sotaques do "povo que faltava", tais como a fala dos ciganos, nordestinos, mineiros, portugueses, dentre outros que viviam dentro e fora da favela no percurso de Minas Gerais até a cidade de São Paulo. Estes são alguns dos traços delineados por uma escrita singularmente híbrida, labiríntica, inaudita e acima de tudo criativa e correspondente. Nesses manuscritos temos novas sugestões registradas a mão, nas quais a autora rearranja o texto para seus futuros editores, empreendendo, desse modo, correções, supressões e o acréscimo de frases ou palavras com outra cor de tinta de caneta ou mesmo a lápis.

Apesar de ter obtido grande sucesso de venda, como o da publicação francesa de Le dépotoir (Stock) - "Quarto de despejo", em 1962, e alguma visibilidade com Ma vrai maison (Stock) - "Casa de Alvenaria", em 1964, o terceiro livro recebeu apenas uma "boa acolhida" da imprensa francesa, mas não partilhou o mesmo sucesso do primeiro. Ainda assim, chegou a ganhar em 1983 um prêmio regional na cidade de Nice: "Prix de Lectrices de Elle", de uma revista feminista de grande tiragem chamada Elle. Na ocasião, a jornalista Pisa, a editora Métaillé e a tradutora Régine Valbert foram até a cidade representar Carolina de Jesus.

Além disso, os direitos autorais de Journal de Bitita foram concedidos à editora espanhola Alfaguara que publicou o livro em 1984, sob o título de Diario de Bitita. Segundo Métaillé na mesma entrevista acima citada, uma editora alemã se recusou a editar o livro alegando falsa autoria. A mesma desconfiança em torno da autoria de Carolina de Jesus gerou polêmica no Brasil no ano de 1993 com artigo "Mistificação Literária”, de Wilson Martins, no Jornal do Brasil (23/10/1993), refutado em seguida por Audálio Dantas (Imprensa, jan./1994, p.42-43) com o artigo "Mistificação da crítica: uma resposta à acusação de fraude literária”. Felizmente, nos dias de hoje, e, sobretudo, após diversos estudos sobre os manuscritos carolinianos, além da materialidade das microfilmagens de alguns 
cadernos disponíveis na base digital da Biblioteca Nacional do Rio de Janeiro, esses questionamentos caíram por terra.

No entanto, o arcaísmo, o passadismo e o preciosismo, quer dizer, essa volta ao passado que contraria os preceitos da literatura praticada nos anos de 1960, ligada ao modernismo e à busca por uma linguagem do cotidiano, afasta Carolina de Jesus do hall seleto da literatura praticada pelos modernistas e possibilita um diálogo insistente com o passado literário. Essa movência é própria de uma prática pós-moderna que coloca o homem em condição de deslocamento, de diálogo com seu passado, sintoma do desnorteamento e de errâncias próprias ao lugar social do homem marginalizado para além de suas condições sociais; um sujeito excluído de sua própria história, como diria Miguel de Unamuno, um sujeito que não está à margem da história, mas está no centro de Outra. Nesse sentido é que a narrativa de Carolina de Jesus avança, a partir de uma linguagem refratada, fraturada, uma poética de resíduos que se equilibra num lugar outro, em detrimento de um indefinido ou indeferido, causando oscilações entre vinculação e desvinculação nos vários espaços temáticos e formais: feminismo, negritude, política, literatura e autobiografia, entre outros.

Não podemos perder de vista que o movimento se faz em dobras, pois o lugar da singularidade, enquanto como marginal periférica urbana, constitutiva do não-lugar ou lugar da negação onde está Carolina de Jesus, consiste justamente naquilo que nos mostrou na tentativa de imitar a língua literária brasileira padrão; mas como não domina os elementos constitutivos da formação para alcançar esse intento, revela os potenciais de uma escrita sui generis que faz referências ao sistema literário ao acaso, constituindo-se de uma maneira orgânica fora dos padrões da língua e de estruturas fundamentais que regem projetos literários como a organização de cadernos e documentos determinados e rearranjados por seus próprios autores.

Uma problemática que torna os manuscritos de Carolina de Jesus ainda mais interessantes e intrigantes, pois se os olharmos sob a ótica dos pós-modernistas, as fragmentações, as dobras ou amontoamentos de elementos nos colocam dentro desse labirinto de sobreposições das recordações que são próprias dessa escrita marcadamente autobiografada, expressando lugares de incertezas da memória, mas também de perambulações pelas estradas, pelos becos e vielas; dos rearranjos dos barracos, dos sobreviventes das rebarbas da cidade, de resíduos de discursos e referencialidades e biografias despejadas em cadernos encardidos e malajambrados que, mesmo após anos, ainda carregam o cheiro do lixo, com exceção para aqueles que foram comprados após a saída da favela. 
Nos cadernos pertencentes ao período de sobrevivência temos uma diversidade de textos escritos ao acaso pelas ruas e esquinas, entre uma pausa para o descanso de uma catação e outra, como nos lembra Vera Eunice: "minha mãe parava o carrinho e escrevia ou falava um poema para mim". No entanto, os que chegaram às mãos das jornalistas pertencem aos últimos cadernos do espólio de Carolina de Jesus. São uma versão das versões mais acabadas das memórias de Bitita e estão organizados no modo com a autora gostaria que chegassem ao público leitor. Este livro, ao contrário do nome escolhido pelas editoras francesas, deveria se chamar "Um Brasil para os brasileiros" e traria um Prólogo da própria autora do modo como podemos ler na seguinte imagem fac-similar:

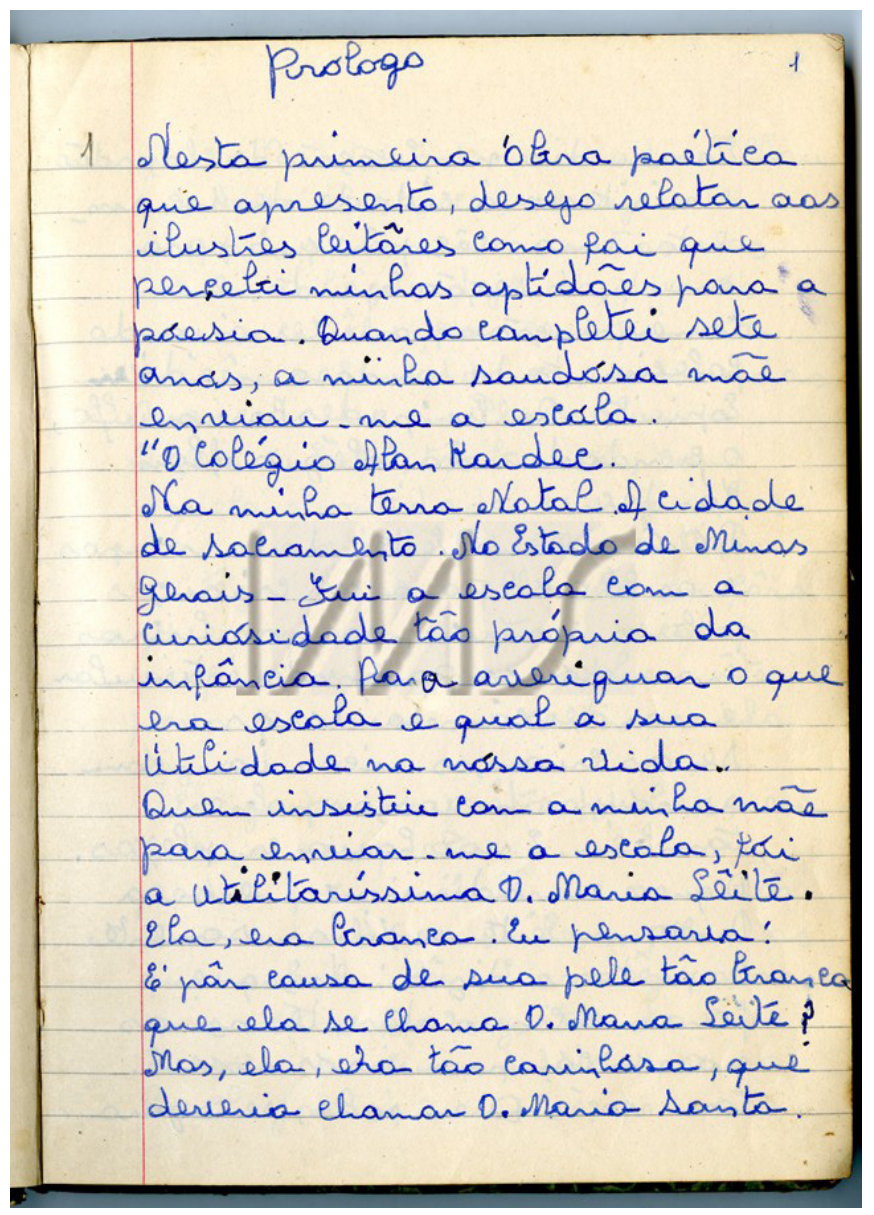

FONTE: Fólio 01 "Um Brasil para Brasileiros" (CMJ, Pi , 001) Instituto Moreira Salles (2014) 
Foram mapeadas sete versões desse mesmo texto, que marca o processo iniciático de Carolina de Jesus no mundo da escrita e da leitura, e que, segundo suas versões, teve sua gênese na escola; porém, em outros manuscritos ela narra a presença do avô, o Sócrates africano - como ela gostava de chamá-lo, em que a figura marcante desse misto de avó-grió não apenas incitava a pequena Bitita para o mundo do saber, como também ao da crítica à condição social dos negros, como a dos moradores ao redor na pequena cidade de Sacramento.

A seguir apresentamos dois exemplos de uma amostra de três versões, acompanhadas do código genético das alterações do mesmo texto, que mostram diferentes momentos do processo criativo da autora e o modo como os diferentes textos (texto 1 e 2 microfilmados pela Biblioteca Nacional e texto 3 no original no Instituto Moreira Salles) apontam para a complexidade de se editar Carolina de Jesus.

\section{Exemplo 1:}

\begin{tabular}{|c|c|c|}
\hline $\begin{array}{c}\text { Miscelânea } 1-\mathrm{BN} \\
\text { (DCS 08795-) }\end{array}$ & $\begin{array}{l}\text { Miscelânea } 2-\text { BN } \\
\quad \text { (DSC 08803-) }\end{array}$ & $\begin{array}{c}\text { IMS -BR IMS CLIT Pi } 0001 \\
(1-63)\end{array}$ \\
\hline $\begin{array}{l}\text { Prologo } \\
\text { Nesta primeira obra } \\
\text { literaria } \\
\text { que apresenta desêjo } \\
\text { relatar } \\
\text { aos ilustres lêitores } \\
\text { como foi } \\
\text { que percebi a minha } \\
\text { aptidão } \\
\text { literaria. } \\
\text { Quando completei sete } \\
\text { anos, a } \\
\text { minha saudosa mãe } \\
\text { enviou-me } \\
\text { a escola. O colégio } \\
\text { Allan Kardec } \\
\text { em Sacramento Estado } \\
\text { de Minas } \\
\text { Geraes. Fui a escola } \\
\text { ignoran } \\
\text { do suas utilidades . }\end{array}$ & $\begin{array}{l}\text { Prólogo }\left({ }^{\wedge}+\text { Prólogo }{ }^{\wedge}+\right) \\
\text { Nesta primeira obra } \\
\text { poética } \\
\text { que apresento desejo de } \\
\text { relatar } \\
\text { aos }\left(\wedge^{\text {aos }} \text { ^)ilustres }\right. \\
\text { leitores, como fói } \\
\text { que percebi a minha } \\
\text { aptidão } \\
\text { poética Quando completei } \\
\text { sete } \\
\text { anós, a minha saudósa mãe } \\
\text { envióu-me a escola,. } \\
\text { O colégio “Allan Kardec”., } \\
\text { na minha terra Natal, } \\
\text { Sacramento, Estado de } \\
\text { Minas } \\
\text { Gerais. (^gerais^) } \\
\text { Fui a escola ignorando } \\
\text { as suas utilidades }\end{array}$ & $\begin{array}{l}\text { Prólogo } \\
\text { Nesta primeira óbra poética } \\
\text { que apresento, desejo relatar } \\
\text { aos } \\
\text { ilustres leitôres como foi } \\
\text { que } \\
\text { percebi minhas aptidões } \\
\text { para a } \\
\text { póesia. Quando completei } \\
\text { sete } \\
\text { anós, a minha saudosa mãe } \\
\text { enviou-me a escola. } \\
\text { "O colégio Alan Kardec. } \\
\text { Na minha terra natal A } \\
\text { cidade } \\
\text { De Sacramento. No Estado } \\
\text { de Minas } \\
\text { Gerais Fui a escola com a } \\
\text { Curiosidade tão própria } \\
\text { da } \\
\text { infância. Para averiguar } \\
\text { o que } \\
\text { era escola e qual a sua } \\
\text { utilidade na nossa vida. }\end{array}$ \\
\hline
\end{tabular}




\section{Exemplo 2:}

Não interessava pelós estudós.

Minha saudosa

professôra

\section{Dona Lonita Solvina}

insistia

comigo para aprender ler.

Eu achava tão dificil

aprender. Implórava a

minha

mãe para não ir a escola

que eu não queria aprender

lêitura. .Ela ouvia-me

Expancava-me e eu ia

contra a minha vontade.

Eu era indolente. Quando

eu
Quem insistiu com a minha

mãe para enviar-me a escola foi a utilitaríssima

Dona Maria Leite

Ela residia em Chapadão

e visitava a cidade de

Sacramento uma vez, pór

ano. Sua visita

anual, era para assistir

a seção espírìta em

comemoração

anivrersáio

esquer

$\wedge^{\text {utilitaríssima }}{ }^{\wedge}$

${ }^{\wedge}$ Chapadão $^{\wedge}$

${ }^{\wedge}$ Sacramento $^{\wedge}$

${ }^{\wedge} \mathrm{Sua}^{\wedge}$

${ }^{\wedge}$ seção $^{\wedge}$

ani[ileg.]

[ileg.]
Quem insistiu com a minha mãe

para enviar-me a escola, fói

a utilitaríssima D. Maria

Lêite.

Ela, era branca. Eu pensava:

É pôr causa de sua pele tão branca

que ela se chama D. Maria leite?

Mas, ela, era tão carinhosa, que

devia chamar D. Maria Santa.

Ela residia na Estação do Chapadão

e visitava a cidade de Sacram-

ento, uma vês pôr ano para assistir a seção Espirita em

comemoração

ao

aniversário do

falecimento do saudoso

médium

Espirita Dr. Eurípedes

Barsanulfo,

o fundador do Colégio Alan

Kardek.

A Dóna Maria Leite, dava roupas

e os livros para as crianças

pobres, as róupas e os livros

eram nóvós para nos estimular

enos deixar vaidósós 
Através do cotejo dessas três versões, pode-se inferir a cronologia estabelecida, de acordo com os arranjos que Carolina de Jesus mobiliza ao longo da criação de possíveis prólogos para seu livro de poemas, mas que no livro Journal de Bitita foi recortado e colado no capítulo "A escola". Como vemos, a versão que consideramos como sendo a primeira apresenta menos preocupação com a escrita, sendo mais solta e podendo, assim, corresponder ao período da escrita mais incerta, improvisada na favela entre muitos fazeres, em meio a intempéries, em conflito com os vizinhos "barulhentos" e adversidades mil. A versão seguinte - talvez num segundo momento de reescritura dessas mesmas lembranças e situações que favoreceram seu ofício de poeta-já carrega marcas de observação da própria escrita, pois a versão 2 traz diversos acréscimos e autocorreções, sobretudo da acentuação e até da caligrafia. Na terceira, a autora parece retomar a versão segunda ampliando os fatos e executando com mais firmeza a gramática padrão, anteriormente em oscilação. Este procedimento converge para o elemento autodidático visível na trajetória desses manuscritos autografados ou datilografados.

Esta é apenas uma amostra da multiplicidade encontrada no espólio de Carolina Maria de Jesus - repleto de surpresas que podem ser vistas como contribuições ao fazer literário cansado e gago de velhas tradições - e que permanece à espera de que sua letra seja publicada no traçado original de seu lápis.

As entrevistas realizadas com as jornalistas e com a editora Marie Métailié me permitiram esclarecer dúvidas, assim como também fazer algumas descobertas acerca dos processos de edição de Diário de Bitita, feita a partir da escrita dos diários de Carolina de Jesus. Primeiramente, publicado em francês (1982), e quatro anos depois traduzido e publicado no Brasil (1986).

A primeira entrevista foi realizada na editora Métailié em Paris, durante meu período de pesquisa, com bolsa financiada pela Coordenação de Aperfeiçoamento de Pessoal de Nível Superior - CAPES -, quando fui investigar a obra de Carolina de Jesus na França. Nessa ocasião, Marie Métailié me mostrou alguns dos datiloscritos que deram origem ao livro. Neles, pude ver diversos tipos de anotações sobre o texto: supressões, acréscimos e correções, de Marie Métailié, de Clélia Pisa e da tradutora Régine Valbert. Enquanto me mostrava o material, ela respondia às dúvidas que foram surgindo e as hipóteses sobre as alterações da forma e do conteúdo na preparação de Journal de Bitita.

A segunda entrevista foi realizada no apartamento da jornalista Clélia Pisa, também em Paris, e no mesmo período da pesquisa de meu doutoramento. As entrevistas são complementares, pois como me informou Pisa, com o passar do tempo, a memória trai aquele que rememora. O diálogo com ela foi fundamental 
para eu compreender como se deu o processo de aclamação de Carolina de Jesus na França, e o modo como a edição desse terceiro livro da autora que, quando publicado lá, reavivou o debate em torno da marginalidade social no Brasil, em várias instâncias: cultural, literária, econômica, sociológica...

A terceira entrevista foi realizada já em terras brasileiras com Audálio Dantas, o "descobridor" e editor de Quarto de despejo. Dantas me deu informações importantes para que se possa compreender o processo criativo de Carolina de Jesus, uma vez que o objetivo deste trabalho é o de rastrear os caminhos das edições que geraram as duas obras que sustentam as memórias da autora, mesmo que se considere que tais edições foram feitas com apoio e intervenção de mãos alheias.

Foi interessante notar que, para todos os entrevistados, é consenso a necessidade de publicação de uma Carolina de Jesus mais genuína, isto é, sem cortes sem reajustes ou traduções. Clélia Pisa foi taxativa em defesa dos escritos de Carolina de Jesus e, nesse sentido, chegou mesmo a ficar chocada quando soube que a publicação de Diário de Bitita que chegou ao público brasileiro é uma tradução do francês para o português do Brasil, e não a compilação dos originais da autora, dos quais a edição francesa se valeu.

Os estudos de cunho etnográfico, histórico e antropológico, ainda que não estejam no foco das minhas análises da obra de Carolina de Jesus, enriquecem e podem esclarecer o contexto em que se deu o processo de escrita dessa obra múltipla e polifacetada. Espero também que, da mesma forma, o material das entrevistas que ora apresentamos, por serem elas recentes e contextualizadas, seja de valia para outros pesquisadores. Não apenas àqueles que estão investigando a obra de Carolina de Jesus como ainda àqueles que se debruçam sobre o contexto literário brasileiro da segunda metade do Séc. XX. 